\title{
TINGKAT PENGETAHUAN DAN KESIAPSIAGAAN MASYARAKAT MENGHADAPI BENCANA GEMPA BUMI DI KOTA PADANG PANJANG
}

\author{
Yola Afrida $^{1}$, Dedi Hermon ${ }^{2}$, Moh. Nasir B ${ }^{2}$ \\ Program Studi Pendidikan Geografi, \\ Fakultas Ilmu Sosial, Universitas Negeri Padang \\ Email: afridayola@gmail.com
}

\begin{abstract}
Abstrak
Penelitian ini bertujuan untuk, mengetahui tingkat pengetahuan masyarakat tentang bencana gempa bumi, mengetahui kesiapsiagaan masyarakat menghadapi bencana gempa bumi dan mengetahui tindakan penyelamatan diri pada situasi dan kondisi. Jenis penelitian ini adalah deskriptif kuantitatif. Subjek penelitian ini adalah masyarakat Kota Padang Panjang yaitu sebanyak 134 orang. Teknik pengumpulan data dilakukan dengan observasi, tes, angket/kuesioner dan dokumentasi. Sampel responden diambil secara proposional random sampling dengan besaran $2 \%$ dari seluruh sampel wilayah. Hasil penelitian sebagai berikut: 1) Di tinjau dari tingkat pengetahuan masyarakat tentang bencana dapat dikategorikan cukup baik. 2) Untuk kesiapsiagaan masyarakat menghadapi bencana gempa bumi dikategorikan kurang siap. 3) Untuk tindakan penyelamatan diri pada situasi dan kondisi dikategorikan kurang siap. Setelah dilakukan penjumlahan ratarata persentase tiap indikator didapat bahwa pengetahuan dan kesiapsiagaan masyarakat menhadapi bencana gempa bumi berdasarkan pengetahuannya masih berkategori kurang siap dengan persentase sebesar 55.05\%, sehingga masih dibutuhkan pengetahuan dan kesiapan yang lebih baik lagi bagi masyarakat untuk mencapai tingkat kesiapsiagaan penuh dalam menghadapi bencana nantinya..
\end{abstract}

Kata Kunci: pengetahuan kebencanaan, kesiapsiagaan, evakuasi,bencana gempa bumi.

\begin{abstract}
This research aims to, determine the level of public knowledge about the earthquake, knowing community preparedness against earthquake and determine the action to save themselves in situations and conditions. This type of research this is a descriptive quantitative. The subjects were community Padang Panjang as many as 134 people. Data collected by observation, tests, questionnaire and documentation. Samples of respondents in this study were drawn proportionally random sampling with the amount of $2 \%$ of the entire sample area. The research results as follows: 1) In the review of the level of public knowledge about disaster can be considered quite good. 2) For community preparedness against earthquake categorized poorly prepared. 3) For self-rescue measures on the circumstances considered less ready. After summation of the average percentage of each indicator obtained that knowledge and community preparedness are confronted by the earthquake based knowledge is still categorized as less ready with a percentage of $55.05 \%$, so it is still necessary knowledge and preparedness are better for society to achieve the level of preparedness full in the face disaster later
\end{abstract}

Keywords: Knowledge Of Disaster, Preparedness, Self-Rescue Actions, Catastrophic Earthquake

\footnotetext{
${ }^{1}$ Mahasiswa Program Studi Pendidikan Geografi untuk Wisuda September 2017

${ }^{2}$ Dosen Jurusan Geografi Fakultas Ilmu Sosial Universitas Negeri Padang
} 


\section{PENDAHULUAN}

Secara geologi, wilayah Indonesia berada pada pertemuan tiga lempeng tektonik aktif yaitu Lempeng Indo-Australia di bagian selatan, Lempeng Eurasia di bagian utara, dan lempeng Pasifik di bagian Timur. Ketiga lempengan tersebut bergerak dan saling bertumbukan sehingga Lempeng Indo-Australia menunjam ke bawah lempeng Eurasia dan menimbulkan gempa bumi, jalur gunungapi, dan sesar atau patahan. Penunjaman (subduction) Lempeng Indo-Australia yang bergerak relatif ke utara dengan Lempeng Eurasia yang bergerak ke selatan menimbulkan jalur gempa bumi dan rangkaian gunungapi aktif sepanjang Pulau Sumatera, Pulau Jawa, Bali dan Nusa Tenggara sejajar dengan jalur penunjaman kedua lempeng. Disamping itu jalur gempa bumi juga terjadi sejajar dengan jalur penunjaman, maupun pada jalur patahan regional seperti Patahan Sumatera/Semangko.

Dampak pertemuan lempeng itulah yang menyebabkan wilayah Indonesia sangat rawan terhadap bencana gempa bumi. Hal ini sudah terbukti dalam beberapa tahun belakangan ini dimana bencana gempa bumi banyak terjadi di berbagai daerah di Indonesia.

Pengalaman memperlihatkan bahwa kejadian-kejadian bencana alam selama ini telah banyak menimbulkan kerugian dan penderitaan yang cukup berat bagi masyarakat. Korban jiwa manusia, runtuhnya bangunan-bangunan, rusaknya sarana dan prasarana dan infrastruktur serta kerugian-kerugian lain yang tidak terhitung jumlahnya merupakan akibat yang ditimbulkan. Permasalahan lain yang dapat memicu kerugian akibat bencana yaitu laju pertumbuhan penduduk yang semakin tinggi dari tahun ke tahun, yang akan membutuhkan tempat tinggal, sehingga akan menyebar pada wilayah-wilayah yang dikategorikan tidak aman, seperti wilayah yang rawan bencana. Permasalahan ini adalah faktor utama yang menyebabkan adanya peningkatan kerentanan bencana. Apalagi masyarakat yang tinggal di daerah rawan bencana sama sekali tidak menyadari dan tanggap terhadap adanya potensi bencana di wilayahnya. Kemudian tingkat pengetahuan yang kurang juga akan menimbulkan banyak kerugian akibat bencana. Untuk itu upaya-upaya yang komprehensif dan berkesinambungan untuk mengurangi potensi dampak kerugian akibat bencana perlu dilakukan.

Sumatera Barat merupakan salah satu daerah rawan gempa di Indonesia. Hal ini disebabkan karena letaknya yang berada pada jalur patahan Semangko, tepat di antara pertemuan dua lempeng benua besar, yaitu Eurasia dan Indo-Australia. Pertemuan atau perbatasan dua buah lempeng inilah yang menyebabkan sering terjadinya gempa bumi di wilayah Sumatera Barat. Termasuk kota Padang Panjang yang sering dilanda bencana gempa dan berpotensi mengalami gempa bumi yang sangat tinggi. Berdasarkan letak geologis dan geografis Kota Padang Panjang maka bencana geologis yang terjadi di Padang Panjang adalah gempa darat yang diakibatkan oleh patahan semangko.

Kota Padang Panjang merupakan daerah yang memiliki dataran tinggi (daerah pegunungan) dengan ketinggian $650-850 \mathrm{~m}$ di atas permukaan laut, temperatur udara yang dingin berkisar antara $18^{\circ} \mathrm{C}-$ 
$2^{0} \mathrm{C}$. Kota ini merupakan salah satu jalur aktif bencana alam, baik berupa gempa tektonik maupun gempa vulkanik yang berasal dari Gunung Merapi, Singgalang, dan Tandikat. Berdasarkan peta Topografi Kota Padang Panjang mempunyai wilayah bergelombang sebagai daerah pegunungan yang sejuk, dengan curah hujan juga tinggi.

Berdasarkan peta Geologi

formasi geologi Kota Padang Panjang terdiri dari batuan andesit dari gunung Marapi, andesit dari gunung Talang dan gunung Singgalang, batu gamping perem dan batuan malihan perem. Kemudian dari struktur geologinya terdapat satu sesar aktif yang melewati Kota Padang Panjang yaitu sesar Bukit Jarat dan satu lagi berdekatan dengan Kota Padang Panjang (pada bagian timur) yaitu Sesar Sumatera.

Dari pengalaman pasca gempa yang terjadi sejak 90 tahun yang silam tepatnya pada 28 Juni 1926, di mana gempa besar melanda Padang Panjang. Pusat Vulkanologi dan Mitigasi Bencana mencatat, "Gampo Padang Panjang" itu menyebabkan lebih dari 354 orang meninggal dunia. Gempa pun menimbulkan bencana di sekitar Danau Singkarak, Bukittinggi, Danau Maninjau, Kabupaten Solok, Sawahlunto, dan Alahan Panjang. Gempa susulan mengakibatkan kerusakan pada sebagian Danau Singkarak. Menurut cerita-serita orang tua terdahulu salah satu penyebab jatuhnya banyak korban yaitu karena kepanikan masyarakat, disebabkan masyarakat banyak yang tidak memiliki pemahaman dan pengetahuan tentang bencana gempa bumi.

Kota Padang Panjang sebagai kota yang dilalui patahan aktif dan diapit oleh tiga gunung menyebabkan daerah ini sering dilanda gempa bumi. Kota ini adalah salah satu kota yang mempunyai intensitas gempa tinggi. Terbukti setiap tahun sering terjadi goncangan baik itu yang terasa bagi masyarakat maupun hanya tercatat pada seismograf. Untuk lebih jelasnya dapat dilihat pada tabel $1 \mathrm{di}$ bawah ini:

Tabel 1. Frekuensi Gempa Menurut

Kekuatan Gempa (SR) Di Kota

Padang Panjang Tahun 2015

\begin{tabular}{|l|c|c|c|}
\hline \multirow{2}{*}{ Bulan } & \multicolumn{3}{|c|}{ Kekuatan gempa / } \\
& magnitude \\
\cline { 2 - 4 } & $\begin{array}{c}\text { M }< \\
\mathbf{5}\end{array}$ & $\mathbf{M}>\mathbf{5}$ & Jumlah \\
\hline Januari & 40 & 6 & 46 \\
\hline Februari & 68 & 3 & 71 \\
\hline Maret & 60 & 8 & 68 \\
\hline April & 22 & 4 & 26 \\
\hline Mei & 20 & 3 & 23 \\
\hline Juni & 30 & 2 & 32 \\
\hline Juli & 32 & - & 32 \\
\hline Agustus & 28 & 1 & 29 \\
\hline September & 60 & 3 & 63 \\
\hline Oktober & 69 & 9 & 78 \\
\hline November & 41 & 2 & 43 \\
\hline Desember & 52 & 5 & 57 \\
\hline Jumlah & $\mathbf{5 2 2}$ & $\mathbf{4 6}$ & $\mathbf{5 6 8}$ \\
$\mathbf{2 0 1 5}$ & & & $\mathbf{2 4 9}$ \\
\hline 2014 & $\mathbf{2 3 7}$ & $\mathbf{1 2}$ & \\
\hline 2013 & $\mathbf{6 0 1}$ & $\mathbf{9 2}$ & $\mathbf{6 9 3}$ \\
\hline
\end{tabular}

Tabel di atas bisa kita lihat bahwa pada tahun 2015 tercatat 568 getaran gempa. Jumlah ini lebih banyak jika dibandingkan dengan jumlah gempa yang terjadi di tahun 2014. Dari total gempa tersebut banyaknya getaran gempa berkekuatan kurang dari 5 skala richter, sedangkan getaran gempa berkekuatan lebih dari 5 skala richter lebih sedikit.

Berhubung dengan keadaan wilayah yang rawan bencana disebabkan terletak berdekatan dengan jalur patahan semangko dan diapit oleh 3 gunung. Untuk itu 
sangat diperlukan pengetahuan dan kesiapsiagaan masyarakat terutama yang berada di wilayah rawan bencana gempa bumi.

Hal inilah yang membuat peneliti tertarik untuk melakukan penelitian tentang bagaimana pemahaman masyarakat menghadapi bahaya bencana alam dengan judul penelitian "Tingkat Pengetahuan Dan Kesiapsiagaan Masyarakat Menghadapi Bencana Gempa Bumi Di Kota Padang Panjang”.

\section{METODE PENELITIAN}

Jenis Penelitian penelitian deskriptif kuantitatif . Lokasi penelitian di Kota Padang Panjang yaitu pada kelurahan Silaing Atas, Pasar Usang, Kampung Manggis, Balai-Balai, Guguk Malintang, Tanah Pak Lambik

Populasi dalam penelitian ini adalah seluruh masyarakat yang berada di Kota Padang Panjang sebanyak 13717 KK.

Sampel responden diambil secara proposional random sampling dengan proposi $2 \%$ sehingga sampel berjumlah 134 orang dari jumlah populasi sebanyak 6.669 orang.

Defenisi operasional variabel dalam penelitian ini sebagai berikut:

1. Tingkat pengetahuan masyarakat

Pengetahuan lebih banyak untuk mengetahui pengetahuan dasar mengenai bencana gempa bumi seperti ciri-ciri, gejala, dan penyebabnya. Pengetahuan yang dimiliki biasanya dapat mempengaruhi terjadinya bencana terutama di daerah rawan bencana.

Indikatornya adalah:

1) Pengetahuan bencana

2) Penyebab gempa bumi

3) Alat ukur kekuatan gempa bumi

4) Bangunan tahan gempa bumi

5) Cara evakuasi
Pengukuran : perangkat tes

2. Kesiapsiagaan masyarakat menghadapi bencana

Sejauh manakah kesiapsiagaan masyarakat tentang bencana gempa bumi sehingga dengan hal tersebut diharapkan dapat memproteksi serta dapat menyelamatkan diri dan keluarga disaat benar-benar terjadi.

a. Indikatornya adalah:

1) Persiapan prabencana

2) Sumber informasi gempa bumi

3) Tempat evakuasi

4) Perencanaan dana

$$
\text { Pengukuran }=\text { skala Guttman }
$$

3. Tindakan penyelamatan diri

Gambaran tentang system penyelamatan diri saat menghadapi bencana gempa bumi di berbagai situasi.

a. Indikatornya adalah

1) Tempat perlindungan dan cara berlindung

2) Pertolongan pertama

$$
\text { Pengukuran }=\text { Skala Guttman }
$$

Sumber data pada penelitian ini melalui beberapa faktor, antara lain:

1. Data Primer, Data primer diperoleh dengan observasi lapangan dan penyeberan kuesioner untuk mendapatkan informasi dari masyarakat

2. Data Sekunder, di peroleh dari kantor dinas kependudukan dan catatan sipil dan instansi terkait dalam penelitian ini.

Adapun bentuk instrument pengumpul data dalam penelitian ini yaitu:

1. Observasi

Dalam melakukan observasi ini peneliti akan langsung turun kelapangan atau lokasi penelitian. 
Peneliti akan mengamati gejala-gejala atau kejadian-kejadian yang terjadi atau kejadian yang ditemui oleh peneliti selama berada di lapangan

\section{Tes}

Dalam penelitian ini tes digunakan untuk mengukur seberapa besar pengetahuan masyarakat Kota Padang Panjang tentang bencana gempa bumi.

\section{Angket atau Kuesioner}

Tujuan penyebaran angket ialah mencari informasi yang lengkap mengenai suatu masalah dari responden tanpa merasa khawatir bila responden memberikan jawaban yang tidak sesuai dengan kenyataan dalam pengisian daftar pertanyaan.

Teknik Analisis Data Sesuai dengan tujuan penelitian, maka data yang di peroleh dari responden diolah dengan menggunakan analisa deskriptif. Analisa data menggunakan teknik deskriptif dinyatakan dalam rumus persentase berikut:

Keterangan :

$$
\mathrm{P}=\frac{f}{n} X 100 \%
$$

$\mathrm{P}$ : proposi

$f$ : frekuensi jawaban responden

$\mathrm{n}$ : jumlah responden

(Arikunto: 2002)

Menurut Arikunto (2006), pengetahuan dibagi dalam 3 kategori, yaitu:

1. Baik = Bila subyek mampu menjawab dengan benar 76\% $100 \%$ dari seluruh pertanyaan.

2. Cukup = Bila subyek mampu menjawab dengan benar 56\% $75 \%$ dari seluruh pertanyaan.

3. Kurang = Bila subyek mampu menjawab dengan benar $40 \%$ $55 \%$ dari seluruh pertanyaan.

$$
\text { Untuk analisis tingkat }
$$

kesiapsiagaan masyarakat menghadapi bencana gempa bumi, dapat dilihat pada tabel berikut ini:

\begin{tabular}{|l|l|l|}
\hline No & \multicolumn{1}{|c|}{ Nilai indeks } & \multicolumn{1}{c|}{ kriteria } \\
\hline 1 & $70-100 \%$ & Siap \\
\hline 2 & $31-70 \%$ & Kurang siap \\
\hline 3 & $0-30 \%$ & Tidak siap \\
\hline \multicolumn{3}{|c}{ Sumber : Hidayati (2006:47) }
\end{tabular}

\section{HASIL DAN PEMBAHASAN}

Sesuai dengan tujuan yang telah ditentukan, maka akan dibahas masing-masing variabel tentang Tingkat Pengetahuan dan Kesiapsiagaan Masyarakat Kota Padang Panjang Terhadap Gempa Bumi dapat ditinjau dari aspek tingkat pengetahuan tentang bencana, kesiapsiagaan masyarakat serta tindakan penyelamatan diri dari berbagai situasi dan kondisi yakni sebagai berikut:

1. Tingkat Pengetahuan Masyarakat tentang bencana

Tingkat pengetahuan masyarakat tentang bencana yang terdiri dari 5 indikator dan terdapat 10 pertanyaan setelah dilakukan penjumlahan persentase dari tiap-tiap soal lalu dibagi dengan jumlah soal didapatkan hasil sebesar $75.45 \%$ atau dalam interval 3 kategori pengetahuan menurut Arikunto (2006), maka dinyatakan pada kategori cukup.

2. Kesiapsiagaan measyarakat menghadapi bencana

Tingkat kesiapsiagaan masyarakat tentang bencana gempa bumi yang terdiri dari 4 indikator dan terdapat 14 pertanyaan setelah dilakukan penjumlahan persentase dari tiap-tiap soal lalu dibagi dengan jumlah soal didapatkan hasil sebesar $31.2 \%$ atau dalam interval 3 kategori kesiapsiagaan maka dinyatakan pada kategori kurang siap.

3. Tindakan Penyelamatan Diri

Tindakan penyelamatan diri masyarakat terhadap bencana gempa 
bumi yang terdiri dari 2 indikator dan terdapat 5 pertanyaan setelah dilakukan penjumlahan persentase dari tiap-tiap soal lalu dibagi dengan jumlah soal didapatkan hasil sebesar $58.5 \%$ atau dalam interval 3 kategori kesiapsiagaan menurut Hayati (2006), maka dinyatakan pada kategori kurang siap.

\section{PENUTUP}

\section{Kesimpulan}

Dari analisis data deskriptif yang diperoleh maka dapat dikemukakan kesimpulan sebagi berikut:

Tingkat pengetahuan masyarakat tentang bencana masih dikatogorikan cukup baik sehingga masih dibutuhkan pemahaman yang lebih baik lagi bagi masyarakat untuk mencapai pengetahuan yang lebih baik lagi terhadap bencana terutama bencana gempa bumi, karena wilayahnya yang sangat rawan terhadap bencana gempa bumi.

Kesiapsiagaan masyarakat menghadapi bencana gempa bumi di kota Padang Panjang dilihat dari tingkat kesiapannya masih tergolong dalam kategori kurang siap sehingga masih dibutuhkan kesiapsiagaan yang lebih baik lagi bagi masyarakat untuk mencapai kesiapsiagaan penuh dalam menghadapi bencana gempa bumi.

Tindakan penyelamatan diri pada saat terjadi dan setelah terjadinya gempa bumi dilihat dari pengetahuannya masih tergolong dalam kategori kurang sehingga masih dibutuhkan pemahaman yang lebih baik lag bagi masyarakat untuk mencapai kesiapan yang penuh dalam mengghadapi bencana.

\section{SARAN}

Adapun saran yang penulis kemukakan dalam penelitian ini adalah sebagai berikut:

Diharapkan kepada masyarakat untuk lebih mempersiapkan diri untuk menghadapi bencana gempa bumi karena kota padang panjang merupakan daerah yang rawan terhadap bencana gempa bumi.

Diharapkan kepada seluruh masyarakat untuk mempersiapkan diri dengan menyediakan tas siaga bencana sebagai persiapan untuk menghadapi bencana.

Diharapkan kepada pemerintah untuk bersama-sama memberikan pemahaman ataupun pengetahuan kepada masyarakat mengenai kesiapsiagaan menghadapi gempa bumi di kota padang panjang, dan memberika penyuluhan secara merata kepada masyarakat

\section{DAFTAR PUSTAKA}

Arikunto S, 2006. Prosedur Penelitian Suatu Pendekatan Praktik, Ed Revisi VI, Jakarta : Penerbit PT Rineka Cipta

Hermon, Dedi. 2012. Mitigasi bencana hidrometeorologi. Padang: UNP Press

Sutton dan Tierney, 2006) (dalam jurnal perencanaan wilayah dan kota) 